\title{
Scanning Electron Microscopy Study of Spark Erosioned Alpha Iron
}

\author{
E. D. Cabanillas*
}

* Consejo Nacional de Investigaciones Científicas y Técnicas and Departamento de Combustibles Nucleares, Comisión Nacional de Energía Atómica, Av. del Libertador 82501429 Bs. As. Argentina; cabanill@cnea.gov.ar

The SEM study of the modification of the surface characteristics of alpha iron produced by electrospark machining using kerosene as dielectric is presented.

The spark erosion or electro- discharge machining process (EDM) [1] [2], is used to cut and conform conductive materials by means of electric discharges, [3] and to produce small particles, [4][5]. The process is mainly thermal involving heating, melting, vaporizing, diffusion and fast cooling, it consists of the swift electric discharge energy strike on a reduced area of two electrodes submerged in a dielectric. The energy surface density is very high and the temperature on the surfaces reaches the melting point and also the boiling point of the electrodes. A bubble is then formed on the electrodes surface till it explodes and the liquid metal is sucked out and thrown out.

Iron metal sheets, $1.5 \mathrm{~mm}$ thickness, 99.95 at.\% purity, Fig. 1, were spark-eroded in a commercial machine (CT Electromecánica, Ltd. ${ }^{\circledR}$, Argentina), with the method of spark-planing at 80V. The discharge duration $t_{0}$ and its current I were chosen between $2 \mu \mathrm{s}-307 \mu \mathrm{s}$, and $3.3 \mathrm{~A}-25 \mathrm{~A}$ respectively. Craters whose diameter depends on the discharge parameters appear on the surface Figs. 2-4 and beneath the material is completely different than the bulk, [6][7]. Austenite, martensite and iron carbides were found when pure iron samples immersed in paraffin were subjected to electro-discharge planing [8] . The layer has a thickness depending on the spark conditions Figs. 5-7 formed by solid phase different to the initial one and to the bulk. Besides of the austenite and martensite different carbides were identified on the surface of pure iron subjected to spark-planed erosion with paraffin as dielectric. In some cases conspicuous frozen structures may be observed on the surface, Figs. 8-9.

Carbon containing phases have been found to form after erosion with electric sparks in an organic dielectric. The inclusion of carbon into the original $\square-\mathrm{Fe}$ coming from the dielectric takes place in a very short time leading to phases out of equilibrium, it is important from the point of view of the technical application of the EDS because the material changes its properties at least in the first microns, due to the incorporation of $\mathrm{C}$ from the dielectric and also to the thermal treatment that takes place during the very fast cooling after the discharge.

\section{References}

[1] Lazarenko, B. R. and Lazarenko, N. I., Physics of the Spark Method of Machining Metals, TsBTI MÉP, Moscow (1946).

[2] Lazarenko, B. R. and Lazarenko, N. I., Machine Tools Cutt. Tools (Moscow) 17(1946), 8; and 18 (1947).

[3] J. E. Fuller, Metals Handbook, Vol.16, $9^{\text {th }}$ Edition ASM International, Metals Park OH,1989 p. 556.

[4] A. E. Berkowitz, M. F. Hansen, F. T. Parker, K. S. Vecchio, F. E. Spada, E. J. Lavernia and R. Rodriguez; J. Magn. Magn. Mat. 254-255 to be published in 2003 1-6.

[5] E. D. Cabanillas, E. E. Pasqualini, M. López, D. Cirilo, J. Desimoni and R. C. Mercader, Hyp. Int. (2001).

[6] E. D. Cabanillas, J. Desimoni, G. Punte and R. C. Mercader, J. Appl. Phys. 782372 (1995).

[7] E. D. Cabanillas, Ph. Thesis, Universidad Nacional de La Plata, Argentina, 1997. 


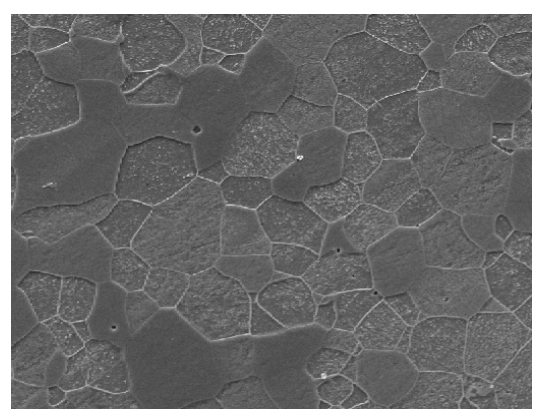

Fig. 1 SEM Metallography of the received material, $700 \mathrm{x}$

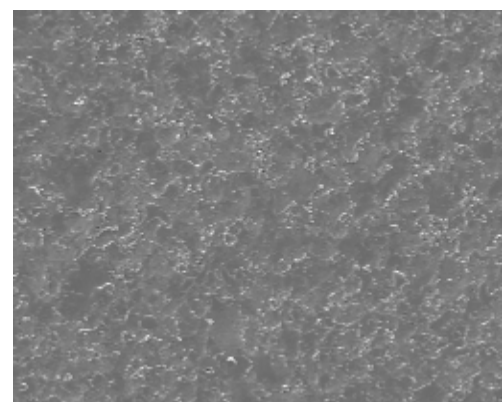

Fig. 3 SEM micrography of 2 $: \mathrm{s}$ and 3.3 A m p electrosparked surface, $300 \mathrm{x}$.

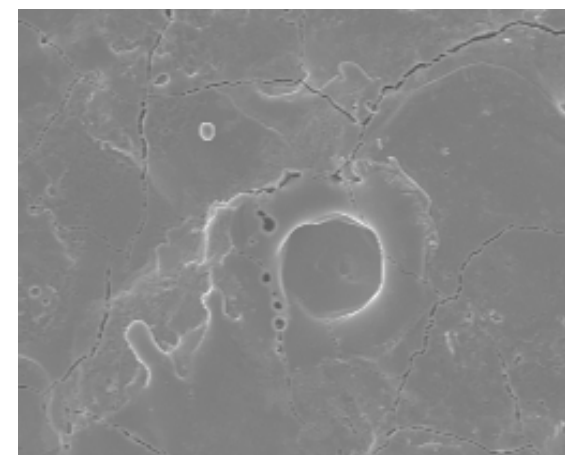

Fig. 2 SEM observation of crater electrosparked by 3.3 Amp and 3072 us $450 x$

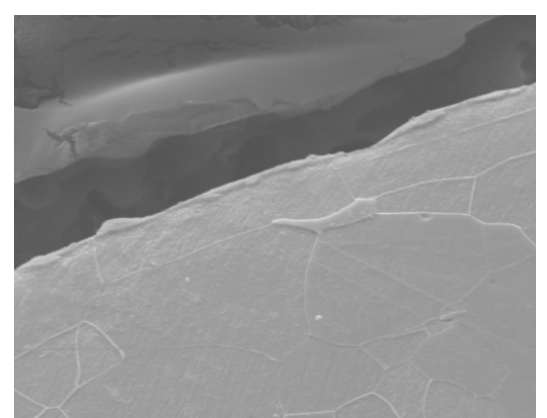

Fig. 7 SEM observation chimmeys and craters obtained with 3.3 Amp and 2 us, $900 \mathrm{x}$

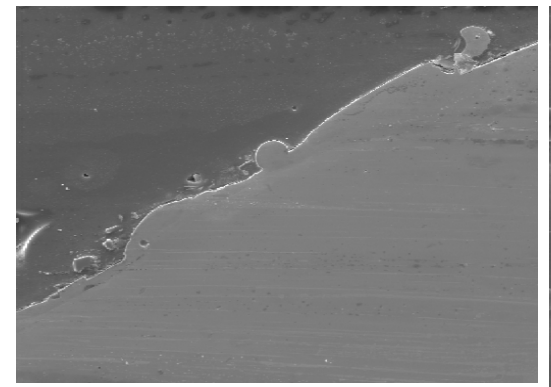

Fig. 6 bordr with frozen ball, 25 amp, 3072 us, 300x
Fig. 9 White zone produced by 3,3 amp and 2 us, $370 \mathrm{x}$

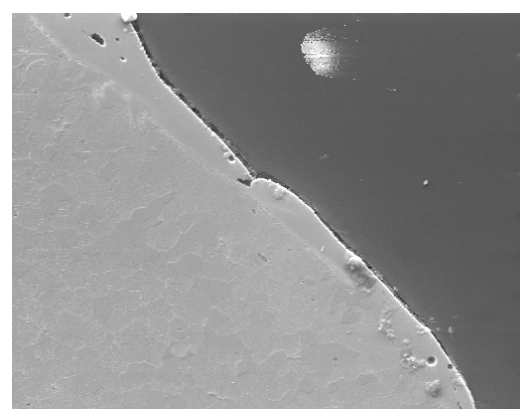

Fig. 8 border of iron elestrosparked with $3.3 \mathrm{amp}$ and 2 us, above the iron structure, 1400x.

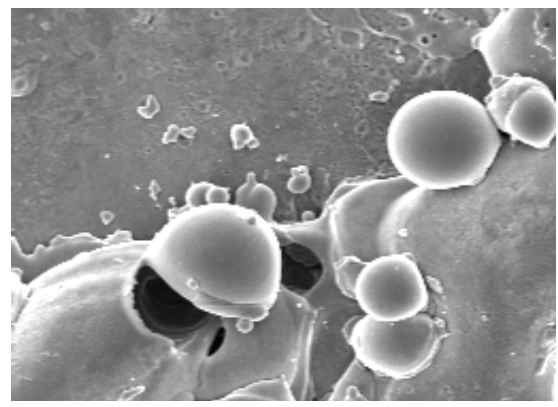

Fig. 4 frozen balls on the Fig. 5 structures formed on the surface of $13 \mathrm{Amp}$ and 2048 us surface of some samples, $420 \mathrm{x}$ electrosparked, $420 \mathrm{x}$ 